\title{
4
}

\section{Liberalism and the \\ Human Good of Freedom}

\begin{abstract}
Among the complaints commonly brought against liberalism, one of the most familiar is that it accords unjustifiable importance to individual freedom. In ideological terms, socialists object that liberalism subordinates equality to freedom, conservatives that it promotes license in the name of freedom, communitarians that it destroys communal ties and engenders unresolvable conflict. In more philosophical formulations, the liberal emphasis on freedom is traced to an ahistorical metaphysical atomism and an empiricism or positivism that are at once jejeune and pernicious. Reflected in an untenable conception of freedom as "negative," as no more than the absence of the crudest obstacles and impediments to physical movement, these ill-considered commitments are said to explain the dangerous incoherence of liberal political and moral thought.

These charges are frequently overdrawn. Insofar as they are directed against the politically organized societies most frequently characterized as liberal (as "liberal democracies"), they of course exaggerate the individual freedom actually available in those societies. In part, these exaggerations consist of overlooking or underestimating interferences with freedom that are condemned (however vigorously and effectively) by the public philosophies that predominate in liberal democracies. But the critics of liberalism also describe incorrectly the place of freedom in influential versions of liberal ideology. It is true that "freedom" and its cognates are prominent in the political discourse of self-styled liberal democracies. It is also true that certain freedoms have been accorded a privileged position in the public law of a number of liberal democ-
\end{abstract}




\section{Toward a Liberalism}

racies. But any moderately close examination of the influential versions of liberal ideology makes it clear that their authors and exponents are not only receptive to but anxious to promote extensive de jure limitations on individual freedom. As libertarians (against whom the charges I mentioned are perhaps more plausibly leveled) complain, freedom is no more than one of a number of liberal values, and liberal publicists have readily found justifications for subordinating freedom to conflicting and competing considerations.

The same observations hold concerning the more abstract and systematic formulations of political and moral philosophers who by self-designation or wide agreement are of a liberal tendency. Just as few among the critics of liberalism declare themselves against freedom properly understood and ordered, so many theorists who by self-declaration or common designation are liberals deny that they hold the views their critics attribute to them. Here again language that arouses the ire of critics is frequently enough encountered; "freedom" and "liberty" are certainly prominent in the work, say, of Locke, Kant, and Constant; Mill, Green, and Hobhouse; Rawls, Dworkin and Ackerman. But Locke's argument for religious toleration, said by Rawls to be a (if not the) decisive moment in the formulation of liberal doctrine, ${ }^{1}$ has been shown to rely crucially on a view about faith that is out of keeping with the secularism characteristic of liberalism and in any case accords religious freedom no more than instrumental significance. Moreover, Locke's theory of political society, so far from being atomistic, privatistic, or even notably impersonal and adversarial, accords a central position to a notion of mutual trust. ${ }^{2}$ As to Kant, while some of the charges I noted may seem justified concerning his specifically political and legal views, attention to the wider moral and epistemological theory that informs those views calls those charges into serious question. ${ }^{3}$

Benjamin Constant was certainly a vigorous champion of "modern" (roughly "negative") freedom against the "ancient," more communal or "positive" variety, and he may be a better object of

${ }^{1}$ John Rawls, "Justice as Fairness: Political Not Metaphysical," Philosophy and Public Affairs I4 (I985):249.

2John Dunn, The Political Thought of John Locke (Cambridge: Cambridge University Press, I969), esp. chap. 4; Rethinking Modern Political Theory (Cambridge: Cambridge University Press, 1985), esp. chap. 2.

3I am indebted here to conversations with George Armstrong Kelly and Bonnie Honig. 
antiliberal polemic than practitioners of that art have realized. If we leave aside the reasons for his relative neglect (at least in the anglophone literature), recent studies show him to have been a man of complex views and perhaps less opposed to "ancient" beliefs and values as such than to indiscriminate conflation of beliefs and values that are and should be kept distinct. ${ }^{4}$ Again, classical utilitarianism, long treated as a form of liberalism, systematically and indeed insistently subordinates individual freedom to utility or the greatest happiness. J. S. Mill, for many the paradigmatic liberal, is famous for a spirited defense of freedom of thought and expression; but well-documented recent interpretations of his thought, ${ }^{5}$ including accounts that absolve him of the cruder antifreedom features that have led recent liberals to disown Bentham and Mill's father, argue persuasively that Mill favored those freedoms primarily because they contribute to self-realization-an idealist or perfectionist concept whose salience in the self-announced liberalism of Green and Hobbhouse has often embarrassed liberals as well as their critics.

To bring this hurried assemblage of reminders up to some present writers, we note that Ronald Dworkin insists that equality, not freedom, is the "nerve" of liberal thought and denies that there can be any right to liberty. ${ }^{6}$ John Rawls opposes the idea that there is a "presumption in favor of something called 'liberty" " and instead argues for a short list of "basic liberties" on the ground that they are necessary to justice or "fair cooperation." Bruce Ackerman's conception of "neutrality" or "neutral dialogue" leads him to insist on a strong form of egalitarianism that would severely restrict a number of freedoms highly valued and strongly protected in self-styled liberal democracies. ${ }^{8}$

Whatever the merits of these particular qualifications on free-

4See, for example, Guy H. Dodge, Benjamin Constant's Philosophy of Liberalism (Chapel Hill: University of North Carolina Press, 1980); Stephen Holmes, Benjamin Constant and the Making of Modern Liberalism (New Haven: Yale University Press, 1984).

5See John Gray, Mill on Liberty: A Defence (London: Routledge \& Kegan Paul, 1983); Fred Berger, Happiness, Justice, and Freedom: The Moral and Political Philosophy of John Stuart Mill (Berkeley: University of California Press, 1984).

6Ronald Dworkin, A Matter of Principle (Cambridge: Harvard University Press, 1985), p. I83; Taking Rights Seriously (Cambridge: Harvard University Press, I977), esp. chap. I 2.

7Rawls, "Justice as Fairness," pp. $232 \mathrm{ff}$. and passim.

8 Bruce Ackerman, Social Justice in the Liberal State (New Haven: Yale University Press, 1980). 


\section{Toward a Liberalism}

dom, it is impossible to deny that individual freedom must be limited in various ways. The most obvious reason for this conclusion is that freedoms often conflict with one another, so that as a practical matter either there will be some sort of standoff or one freedom must take precedence over another or others. Because freedom and its values will be on both or all sides of such conflicts, the conflicts cannot be resolved without appeal to considerations other than freedom itself. ${ }^{9}$ Beliefs and values not reducible to convictions about freedom necessarily enter into thought and action about freedom. Moreover, the recurrence in our tradition of distinctions such as between freedom and license is powerful evidence that further limitations will be thought necessary. In bare principle it is not impossible that "license" and related notions could be restricted to cases in which one or more sets of freedoms are in conflict; in even barer principle it is perhaps conceivable that conflicts between and among freedoms might be resolved in terms of some notion of maximizing freedom. But the latter combination of ideas may well be incoherent, ${ }^{10}$ and notions such as license are in fact regularly and potently invoked in the name of numerous beliefs and values other than freedom itself. In attending to these matters, liberal theorists have done what any theorist must do.

We will be better placed to accommodate freedoms to one another and to harmonize freedom with other concerns if we have a clearly formulated view of why freedom is valuable. Critics of liberalism write as if "it" already includes such a formulation. If taken to mean that there is a view that is at once well articulated and widely accepted among those of a liberal persuasion, this suggestion is manifestly false; it would perhaps be more accurate to say that freedom has often been verbally honored but seldom clearly located or effectively defended in liberal thought; it is in any case undeniable that a number of the liberal writers who have considered the matter more closely have put freedom in a subordinate, perhaps a less than secure, position.

We find ourselves, then, in a complex and perhaps anomalous situation. Vociferous opponents of liberalism attribute to it an uncritical and unjustifiable commitment to individual freedom, an attribution that finds some support in the rhetoric of self-styled

${ }^{9}$ See H. L. A. Hart, Essays in Jurisprudence and Philosophy (Oxford: Clarendon Press, I983), esp. chaps. 9 and Io.

${ }^{10}$ Cf. Dworkin, A Matter of Principle, p. 189. 
liberal practices, ideologies, and theories, much less warrant in the details of those practices, ideologies, and theories. Thus (a) if liberalism does (or, consistent with other of its commitments, should) accord individual freedom the place its critics allege, it (b) might deserve the condemnations the latter direct against it. On the other hand, if (c) freedom deserves something akin to the place that critics allege liberals accord it, then liberals are subject, rather, to the criticism that (d) they do not clearly, or (e) clearly do not, accord freedom the place their detractors say they accord it.

Of these possibilities, I am disposed to (a) and (c), disposed against (b), and I argue accordingly in the remainder of this essay. I have already indicated my sympathy for (d) and (e), but for two reasons that are connected with each other and that influence my mode of argument concerning (a), (b), and (c), I will not offer further support for them here. First, (d) and (e) are propositions in intellectual history and in historical and contemporary political sociology. Confirming or disconfirming them would require detailed exegetical and otherwise empirical investigations well beyond the scope of this essay. Second and more important, to confirm or disconfirm (d) and (e) as propositions about liberal practices, ideologies, and theories would require that I abandon evasive phrases such as "self-declared" and "generally agreed" and specify the permissible range of the concepts "liberal," "liberalism," and the like. An account of the views about freedom of Bentham, or Mill, or Rawls, however well documented and convincing, would count for or against (d) and (e) only if it had also been established that they are (in the respects in question) properly regarded as liberal theorists. Even if it is in principle possible and desirable to settle this question (I have serious doubts on both but especially on the second score), it is obvious that I cannot hope to settle it here. Accordingly, I argue as best I can for a conception of the value of freedom. I call my conception "liberal" and I summon certain considerations in support of that designation and on behalf of the claim that the conception is an improvement over those offered by other self-identified liberals. But for present purposes the merits of the conception must be more important than the merits of calling it liberal.

Two further caveats before starting off. First, throughout I assume and employ a "negative" concept of "freedom" and "unfreedom." "Freedom" and "unfreedom" are predicates of human actions. Roughly, actions are taken by (and hence talk of both 


\section{Toward a Liberalism}

freedom and unfreedom presupposes) persons who are "agents," that is, persons who, in the setting of a community with a shared language and the elements that Wittgenstein and others have identified as necessary to such a language, form and hold beliefs; form desires and interests, objectives and purposes, that are influenced by their beliefs; frame intentions to act to satisfy their desires, interests, and so forth; and attempt to act on their intentions. Agents and actions are free insofar as their attempts to act are not prevented, impeded, or deflected from their objectives by the actions of other agents, and are unfree insofar as they are prevented, impeded, or deflected by the actions (including deliberate refusals to act) of other agents. In the absence of agency or action there is no "freedomevaluability," nothing of which either freedom or unfreedom can be predicated. I have elsewhere defended this use of the concepts against arguments proceeding from various "positive" construals of them (and against the view that there are no significant differences between negative and positive formulations), and I can only refer readers who are skeptical on these points to that discussion. ${ }^{11}$

Second, the view of freedom I advance is general in character and therefore cannot itself dictate resolutions of particular conflicts among freedoms or between freedoms and other desiderata. If coherent and convincing, a general view of the value of freedom can influence and in some measure discipline the continuing task of arriving at circumstantial and revisable accommodations and harmonizations, but it cannot itself perform or displace that task. This feature of general theories is not infrequently overlooked or denied by theoreticians who claim that specific distributions of freedoms or of restrictions upon them are required by their theories. A subsidiary theme of this essay, connected in ways that I do not myself fully understand with my argument about the value of freedom, is that liberals (even if they can agree on few other things) ought to stand against such conceptions of the theory-practice relationship.

Among other things that they are, human beings are desiring, interest-pursuing, end-seeking, purposive creatures. Partly because

${ }^{11}$ Richard E. Flathman, The Philosophy and Politics of Freedom, pt. I (Chicago: University of Chicago Press, 1987). 


\section{Liberalism and Freedom}

of the character of their interests and desires, ends and purposes, and partly because of characteristics of the environment in which they live, in most cases they must take action to achieve their ends. Given these characteristics of human beings and their environment, freedom of action is a high-order human good, a condition or state of affairs on which human beings will, and in reason should, place high value. The value of freedom is not tied to a particular inventory of interests and desires, ends and purposes. The content or substance of human interests and desires varies from one person to the next and often changes substantially during the life history of a single person. Freedom is a good of great general value because it is necessary to the satisfaction of a great many interests and desires, the achievement of many ends and purposes, and contributive to the satisfaction and achievement of yet many more. Unfreedom is a serious evil because it prevents or inhibits achievements and satisfactions and produces frustration, distress, and harm.

There is a certain commonsensical quality to the foregoing remarks. If or insofar as we understand human beings in the ways I have employed, it seems obvious that a substantial freedom, a generous area of discretionary action, will be something valued by them and valuable to them. On the face of things, it is not easy to see how it could be denied that human beings have these characteristics or that, having them, freedom will be valuable to them.

In fact, however, there is nothing necessary, nothing rationally undeniable or indisputable about this reasoning or its conclusions. Empirically, we know of people who have very few desires, purposes, and the like, and of others who, owing to the combination of the character of their desires and the fact that their circumstances are especially favorable or unfavorable to satisfying them, have been understandably (if shortsightedly) indifferent to freedom. We are also familiar with thought experiments that imagine changes in human beings and their environment which would, if implemented, require us to qualify or abandon the reasoning. Finally, human beings and the human environment have features other than or additional to those on which my reasoning relies. Readers of these essays do not need to be told of the many attempts to ground normative thinking about freedom in considerations quite different from those I have urged.

It will emerge that the most important type of objection is the last one mentioned. But the more (or at least initially more) empirical 


\section{Toward a Liberalism}

objections require consideration in their own right, and examination will show that they merge into the difficulty last mentioned.

My initial response to the objection that the above reasoning misrepresents the facts on which it relies is as follows: perhaps the project of developing a general argument for freedom as opposed to particular freedoms is misbegotten. Perhaps such arguments will either be so abstract as to be vacuous or so hedged with qualifications as to be useless. But if there are to be such arguments, and if such arguments are to be based in part on facts about human beings, they will have to rest upon generalizations, not upon universal truths. The significant question about the reasoning I sketched is not whether we can identify exceptions to the generalizations I advanced about human beings and their circumstances; rather the question is whether exceptions occur so frequently as to make it clumsy and distracting to rely on the generalizations in forming a general orientation toward or perspective concerning freedom. If we accept the reasoning I sketched, we will approach concrete issues concerning freedom with a certain set of expectations and with concepts and principles in which and with which to assess what we actually encounter. If our expectations are confuted, if our talk of the importance of freedom to satisfying desires and interests, achieving ends and purposes, regularly elicits incomprehension or hostility, what was intended to be a simplifying and facilitating move will complicate and divert our reasoning and our judging. Rather than being able to subsume particulars under agreed categories and principles, we will have to defend the generalizations on which our categories and principles depend. But if this happens only rarely or exceptionally we will (so far as the objection I am considering is concerned) be justified in taking our bearings from those generalizations so long as we remain alert to the possibility of exceptions to them.

There is every reason to believe that the reasoning I sketched would be irrelevant or distracting in numerous societies and cultures. Implicit in that reasoning is an understanding that I earlier called the liberal principle, or LP: namely, that it is prima facie a good thing for individuals to form, to act on, and more or less regularly to satisfy (their) interests and desires, their ends and purposes. ${ }^{12}$ But this idea has or has had little or no acceptance, little or

12Richard E. Flathman, The Practice of Rights (Cambridge: Cambridge University Press, I976), pp. 7-8, 44-47, I67-8I. 


\section{Liberalism and Freedom}

no standing, in numerous cultures and societies. Some cultures have regarded desires and interests, particularly desires and interests of individual persons, as prima facie or even categorically bad or wrong. The first, perhaps even the exclusive, concern has been to abide by the divine laws and commands, to discharge duties assigned by the collectivity, to pursue the common good, advance the mission of the church, the class, or the party. Individual interests are to be subordinated if not rooted out. If individual freedom has been valued at all in such societies (and characteristically such societies prize the authority of the collectivity over its individual members, the freedom of the collectivity vis-à-vis other collectivities), it has been not for the reasons I sketched above but because individual freedom (or the freedom of certain select types of individuals) enhances extra- or supra-individual goods and ideals. If one argued for individual freedom on the grounds I sketched, one would be arguing against - not from - the prevailing conceptions of, the prevailing beliefs about and values concerning, human beings.

The foregoing remarks underscore the underdefended character of the reasoning I presented for the value of freedom. The factual generalizations I advanced may be true of only some cultures and societies. But even if they are quite generally true, they will be accepted as elements in an argument for freedom only in societies in which they are positively valorized. A premise in my reasoning is axiological in character and attributes positive value to the state of affairs described by the empirical generalizations I advanced about human beings and their circumstances. LP is one possible formulation of such an axiological premise or principle: human beings do, or should, not only recognize but accept that they are desiring, interest-seeking, end-pursuing, purposive creatures whose wellbeing consists in important part in being able to pursue and satisfy their individual interests and desires, ends and purposes, and whose well-being is therefore enhanced by circumstances that are conducive to their doing so.

It is clear that premises of this character have been entirely rejected (or never considered) in some human societies and have been accepted only with severe qualification in numerous others. But it seems equally clear that premises of this character have been promoted to the standing of principles by persons influential in the shaping of modern Western societies and are in fact widely influential among the members of those societies. The fact that my sketch, 


\section{Toward a Liberalism}

abbreviated as it is, is intelligible and even commonsensical can perhaps be taken to testify to the correctness of these assumptions. The sketch is intelligible because it proceeds from, is a modest elaboration on, thinking that is widely received in modern Western societies.

My sketch is nevertheless eminently disputable, disputable from within the confines of thinking widely received in the societies in question here. It can be controverted without adopting ascetical, perfectionist, or collectivist views more radical than those influential in the societies in question. One way to dispute it is to argue that it provides too weak an argument for freedom. By making the value of freedom instrumental to the good that is the pursuit and satisfaction of interests and desires, ends and purposes, it leaves freedom's value hostage to psychological and cultural contingencies. The value of freedom may be augmented by considerations such as those I have adduced, but its deeper grounding is, or should be made, more secure. Freedom is an inherent or intrinsic, not an instrumental, good. Or at least its value in human life is due to features of human beings that are less variable, less culture specific or dependent (and more noble, elevated, or at least dignified?) than "interestedness," "desirousness," and purposiveness.

Intrinsic, inherent, and related terms are sometimes used as epistemological concepts signaling a direct or unmediated intuition or other apprehension of truths about which evidence or argumentation other than the experience of the intuition itself are impossible or irrelevant. The deepest difficulties with this notion need not be rehearsed here. It suffices to say that, as a moral and political matter, this view engenders dogmatism and helps not at all in resolving questions about conflicts among freedoms and between freedom and various other goods.

Leaving aside arguments about freedom as opposed to determinism (metaphysical freedom) and about physical movement as distinct from action, it will nevertheless repay us to consider one further version of the idea that freedom is an intrinsic, not merely an instrumental, good. The argument in question is that both the fact of and a high regard for freedom of action is one of the deepest conventions of and, in that Wittgensteinian sense, a starting point of thought and action in our culture. It is intrinsic to our moral and political practice in the normative sense that any practice that is deeply incompatible with or generally destructive of freedom of 


\section{Liberalism and Freedom}

action is therefore, without the need of further evidence or argumentation, deemed unacceptable. We do not argue for the value of freedom: our moral and political argumentation starts from, is premised on, its value. This view is consistent with dispute as to what counts as freedom and unfreedom, as to whether this or that arrangement or action serves or disserves freedom, and whether freedom in this or that respect should properly be subordinated or sacrificed, here and now, to some other value or good. But arguments against freedom as such, and hence arguments for policies and practices that are categorically or even generally antifreedom, are not countenanced.

Something like this sense of freedom as an intrinsic good is involved in Stanley Benn's discussion of the principle of noninterference (PNI). ${ }^{13}$ Insofar as we have made it a principle that the burden of justification falls on anyone who proposes to interfere in or with the actions of other persons, our day-to-day reasoning begins with the idea or belief that freedom is a high-order good. Interferences with freedom must be justified in the face of or despite the fact that they contravene or diminish that good. The fact that we entertain and accept such justifications shows that freedom is not an absolute in the sense of a good that takes precedence whenever it is involved or at issue. But it is an intrinsic good in the sense that it is a feature of our practices that must be understood in order to comprehend those practices and one that must be accepted in order to participate intelligently and defensibly or respectably in them. An observer who did not grasp what might be called the constitutive character of the good would fail to understand much of what goes on among us; the actions and arguments of participants who did not grasp the standing of that good would almost certainly-that is, apart from quite remarkable coincidences-meet with antagonism or incomprehension from other participants.

Unlike the first construal of "intrinsic" I considered, this one does not exclude the possibility of arguments for the value of freedom. Of course the claim that the good of freedom is intrinsic in this sense suggests that such arguments will rarely be encountered in explicit form: for the most part arguments for the good will be unnecessary in the sense that they will be redundant. It may even be difficult for

13Stanley Benn, "Freedom, Autonomy, and the Concept of a Person," Proceedings of the Aristotelian Society 76 (1976):109-30. 


\section{Toward a Liberalism}

participants to think of considerations, independent of the good, in terms of which to argue for its standing as such. But this difficulty is social-psychological, not logical or epistemological in character, and there are reasons for thinking that it is valuable to do what we can to overcome it.

Leaving aside reasons that hold for all of our beliefs and values (for example Socrates' view that the unexamined life is not worth living, J. S. Mill's view that people who do not know, or who have lost sight of, the reasons for their beliefs and values do not fully know what they believe and value), two such reasons are especially pertinent. The first is grounded in the fact that freedom of action as a high-order value is rejected in many cultures and societies. If it is true that the value is deeply embedded in modern Western societies, it is important that those who reject or challenge it understand that, and why, this is the case. It may be a kind of response to such challenges to say, "This is what we think; this is how we do things hereabouts." It may even be that disagreements about the value of freedom of action, as with differences of religious belief, run so deep that mutual understanding and accommodation is the best that, or even more than, can be hoped. But even this modest objective is furthered if the parties to the disagreements can articulate for themselves and to others the grounds on which their views rest.

The second reason is grounded in two facts. I have already mentioned the first of these, namely, that we experience freedom and its value and disvalue by exercising various freedoms, and these freedoms sometimes conflict with one another and with other of our values. Conflicts among freedoms could be resolved by appeal to the value of freedom per se only if we could make sense of the notion of maximizing freedom, and in any case such an appeal would resolve conflicts with other values only if we elevated freedom to the top of a strictly hierarchical value structure (to first position on a lexically ordered list of values), that is, only if we made freedom an absolute as well as an intrinsic value. Having more rather than less clearly delineated general reasons for valuing freedom of action will not settle, certainly it will not still, all questions about the comparative importance of freedom or of various freedoms. But it would be irrationalist or antirationalist to assume that no such reasons are available or that having such reasons will be of no use in resolving such issues (or at least in remaining civil with one another as we attempt such resolutions and as we live with our no more than partial successes). The second of these facts is that there is lively 


\section{Liberalism and Freedom}

controversy in the literature of moral and political philosophy concerning why freedom should be valued and how its value should be compared with a variety of other desiderata. In addition to being intellectually engaging in its own right, this controversy reflectsalbeit no doubt imperfectly-issues, positions, and arguments that are prominent outside of philosophical books and journals.

To summarize this stretch of discussion, it is plausible to treat freedom of agency as an intrinsic good in our moral and political practices in the sense that its being a good is a datum in or of those practices. If so, the fact that it is no less than a datum is vital to understanding and to participation in those practices. The fact that it is, qua intrinsic good, no more than a datum means that the question of why freedom of agency should be valued (and hence, finally, whether and how much it should be valued) invites our reflection. Because this version of the idea that freedom is an intrinsic good is the only one that is both plausible and pertinent to our present concerns, I can summarize the discussion of that beguiling idea by restating my original contention: freedom of agency is a contingent and an instrumental good, albeit one that is contingent on factual generalizations about human beings that are difficult to dispute and instrumental to values that are widely shared and deeply established in modern Western societies.

I henceforth refer to the belief-cum-principle that freedom is a high-order good as the general presumption in favor of freedom, or GPF. On the reasoning I have thus far given (as distinct from my claim that something like this belief-cum-principle is a datum of our culture), GPF is an inference from (not an entailment of) the evaluations expressed by principles such as PNI or LP. If we accept these evaluations, we have reasons to endorse and to act on GPF. For present purposes the question then becomes whether we can further strengthen the case for GPF as a general presumption or principle of thought and action.

Disposed as I am to defend GPF, I will treat this question as how best to argue for it. But of course pursuing this objective requires identifying and assessing the merits of arguments against the principle.

Continuing to work with the sketch I first set out, the chief task is 


\section{Toward a Liberalism}

further to defend LP or some principle analogous to it. I say this because the other main elements in the argument, generalizations about human beings and their circumstances and about features of our culture, are less likely to be disputed. Of course there is no shortage of objections to self-interest and its pursuit or to desires and desirousness (albeit arguments against end seeking and purposiveness are rare, a point to which I return below). But most such objections, certainly within our culture, are to the effect that human beings should not do these things or should subordinate the doing of these things to other of their activities, other of their characteristics. People who advance such arguments typically allow that the generalizations are (all too) accurate concerning human beings as we in fact encounter them in our culture. Their contention is that these characteristics are unfortunate and that the freedom to indulge them is anything but a good thing.

The first task, accordingly, is to defend the idea that it is good for human beings to form, to act on, and to satisfy interests and desires. If this idea can be defended, the further ideas-that freedom of action is a high-order human good and that a heavy burden of justification should fall on those who propose to limit, qualify, or interfere with it--will be easier to defend.

The most uncompromising opposition to LP comes from proponents of various forms of asceticism or self-denial. In considering this source of objections we should first note that at least some of their force is blunted by attention to the elements out of which LP is formed and to the formulation of LP itself.

Asceticism is at its apparently most potent (at least in its secularized forms) when it objects to desires and desire satisfaction, particularly when it interprets desires as passions that "well up in," "take over," and otherwise supplant or obliterate the more rational, the more disciplined, the higher human faculties. Surrendering to these passions, "wallowing in them" in the sense of letting them and their satisfaction become the sole or primary raison d'être of one's existence, is "de-grading"; instead of living up to one's "grade," one's capacities or potential as given by God, or nature, or the culture into which one is born, the desirous, sensual, hedonistic person sinks to or below the level of nonhuman animals. Insofar as the sensualist can be said to have an aim or project, that project is self-defeating. Desires beget desires in a "bad infinite" that may spiral down to "polymorphous perversity" and that in any case 
excludes the possibility of more than ephemeral, more than unsatisfying satisfactions.

This picture is implausible if desires and action on desires are properly understood. ${ }^{14}$ Beliefs that are subject to correction and if corrected will alter the desire, identification of objects that will satisfy the desire, choice of courses of action likely to attain those objects-all of these are features of desires and actions to satisfy them. None of this prevents desires from being unseemly, debased, or repugnant to others, and it certainly does not guarantee that the actions taken to achieve them will be acceptable to others. But the idea that forming and acting to satisfy desires is itself an abandonment of the true or higher human capacities is largely a misunderstanding. The unqualified, necessarily debased sensuality attacked by asceticisms from fourth-century anchorites to Schopenhauer is in the realm of behavior, not desires and action on desires. There may be a case for freedom of such behavior, but it is not the same case as the case for freedom of action.

The second element in LP-namely, interests and attempts to serve them-is most commonly attacked not on the ascetical ground that it is degenerate but rather that it is narrowly calculating, egoistic, and socially divisive. The "interested" person uses her capacities for discernment, judgment, and evaluation, but she does so with no more than instrumental regard for others and hence, on some formulations of anti-interest argumentation, shortsightedly from the standpoint of her own larger or longer-term interests. As the last clause reminds us, however, the objection that actions motivated by interests are selfish in antisocial or immoral ways, or even imprudent, is contingent on the character of certain interests and certain strategies for satisfying them. Notions such as Tocqueville's "enlightened self-interest" and J. S. Mill's “permanent interests of man as a progressive being" (and of course yet wider uses of the concept such as in the philosophies of Ralph Barton Perry and Jürgen Habermas) make it clear that these objections have no application against much thought and action standardly characterized as "selfinterested."

It is no part of my intention to deny that much that occurs in human affairs in the name of desires, interests, and their pursuit and satisfaction is objectionable and-albeit this is a further point-

${ }^{14}$ I rely here on an analysis of desires and interests presented in part I of Flathman, The Philosophy and Politics of Freedom. 


\section{Toward a Liberalism}

justifiably prevented. But recognizing this provides no reason for objecting to LP. LP says that it is prima facie a good thing for human beings to have, to act on, and to satisfy desires and interests. If categorical objections to desires and interests (or "desirous" and "interested" conduct) are without merit, it remains open to us to adopt LP and the presumption it establishes in favor of human desires and interests and then to consider arguments that this or that desire or interest, as pursued in these or those circumstances, is nevertheless objectionable. Nor does this stance or strategy debar the conclusion that certain subclasses of desires and interests are generally objectionable and to be discouraged. If we are committed to LP we will, of course, view such reversals of the burden of proof with suspicion; but the logic of the principle itself, featuring as it does both "prima facie" and the comparative notion of "good," requires that we remain open to the possibility that they will sometimes be justified.

Aside from the last comments about LP, my remarks thus far are modest elaborations of the point that the concepts "desire" and "interest" are situated in the Wittgensteinian sense that they are part of a conceptual system governed by widely accepted conventions and rules. Although capacious in that they accommodate a wide range of beliefs and objects, they are concepts, not mere words or markers, "somethings," not "anythings." The desires and interests that we can form and pursue are restricted in ways either misunderstood or ignored by ascetical critics.

The conventions and rules that govern "desire" and "interest" are, of course, open textured and subject to change. They are part of language-games and forms of life that are internally complex and changeable and that are influenced by activities and developments more or less independent from them. I am not suggesting that there is a fixed inventory of possible interests and desires or that either the fear of declension or the hope of an ascension in their usual or predominant character is necessarily misplaced or misbegotten. But attention to secular tendencies in the language-games of desire and interest will further disqualify the more fervid concerns that they sometimes arouse.

According to Albert Hirschman, the concepts of interests and self-interest came into prominence in Western thought in contrast with and as means of controlling the very notions-that is, "passions,"-to which ascetical and anti-interest writers are prone to assimilate them. Further abbreviating a complex story that Hirsch- 


\section{Liberalism and Freedom}

man himself has severely compressed, as confidence declined that reason (and, one should add, faith and its discipline) could control the violent and destructive passions, the idea developed that interests could help to tame them, to domesticate them sufficiently to make peaceful social life possible. Denoting "an element of reflection and calculation with respect to the manner in which [human] aspirations were to be pursued," 15 interests came to be regarded as more potent sources of motivation than abstract reason and yet less divisive and destructive than passions. "Once passion was deemed destructive and reason ineffectual, the view that human action could be exhaustively described [in their terms] meant an exceedingly somber outlook for humanity. A message of hope was ... conveyed by the wedging of interest in between the two traditional categories. ... Interest was seen to partake in effect of the better nature of each, as the passion of self-love upgraded and contained by reason, and as reason given direction and force by passion."16

On the view of interests Hirschman describes, severely ascetical forms of anti-interest argumentation are not only archaic but selfdefeating in that they demean and condemn the forms of motivation-cum-reason for action most likely to prevent degeneration to the unbridled and destructive sensuality that those who advance such arguments fear and despise. Strikingly, the "element of reflection and calculation" of which Hirschman writes corresponds closely to features still "denoted" by "desire" as well as by "interest."

In an analysis that endorses but extends Hirschman's, Stephen Holmes develops further themes pertinent here. Focusing primarily on seventeenth- and eighteenth-century materials, Holmes argues that interests were distinguished from and preferred to notions of privilege and paternalism. The allegedly more elevated character of the latter bases for and motivations to action came to be viewed as a device for giving a spurious legitimacy to social and political arrangements that were oppressive insofar as they were effective and increasingly ineffective in maintaining peace and order:

Liberals turned a friendly eye toward self-interest to discredit the degrading ranks of prestige and chains of dependency characterizing the old regime.... By focusing on [desires and] interests, and by

${ }^{15}$ Albert Hirschman, The Passions and the Interests (Princeton: Princeton University Press, 1979), p. 32.

16Ibid., p. 43. 


\section{Toward a Liberalism}

attributing paramount importance to self-preservation, Hobbes strove to put an end to the English Civil Wars. His aim was not to promote the interests of the merchant class, though that may have been a side-effect of what he did. By discrediting [for political purposes] the ideals of glory and salvation, he hoped to encourage peace. ${ }^{17}$

Holmes's remark about the merchant class alludes to objections to interests and interest-oriented conduct that became familiar after the period he is discussing; but the arresting feature of the contrasts he is most concerned to draw is that they are between, on the one hand, the desires and interests promoted by liberals and by Hobbes and, on the other, forms of thought and action that in fact are selfindulgent and self-defeating in just the ways attributed to desires and interests by severe critics of the latter. Holmes's liberals distinguish claims based on shareable and, in principle, mutually reconcilable desires and interests from entitlements of place and privilege which are insisted (by their holders and defenders) to be incommensurable with such desires and interests. Because the entitlements are regarded by their claimants as intrinsically superior, they can be accommodated to or harmonized with the ordinary run of desires and interests only in the weak sense that the latter might be given consideration after the superior entitlements have been fully honored. Holmes's Hobbes distinguishes desires and interests, which can be pursued and satisfied by all members of a society, from ideals of character and conduct, which their partisans at least tacitly concede to be unshareable or at least undistributable. In fact, however, the privileges the liberals attacked are self-, class-, or casteindulgent in at least two senses: (a) they are excessive in demanding a gross superfluity of wealth and power, and (b) they are unjustifiably exclusive in that they are restricted to a small and assignable number of persons or to specific classes or castes with fixed memberships. Because of these characteristics, claims to the privileges are self-defeating: if satisfied they corrupt their beneficiaries at the same time that they harm those from whom the benefits are extracted; the corruption of the former and the oppression of the latter delegitimate the claims to them so that the claims must either be abandoned or enforced by tyrannical means that are costly in themselves and that sooner or later incite revolts that destroy the system of privileges. The ideals of character that Hobbes attacks are

${ }^{17}$ Holmes, Benjamin Constant and the Making of Modern Liberalism, p. 253. 


\section{Liberalism and Freedom}

(again from a political standpoint) self-indulgent in the sense of having an exclusivity closely analogous to that already discussed (they are aristocratic ideals) and self-defeating because conduct in pursuit of them is incompatible with a society stable enough to allow such conduct to flourish. By comparison with both the privileges and the ideals, the allegedly self-indulgent and self-destructive desires and interests are shareable and are supportive of a peaceful and stable social and political order.

The particular passions, privileges, and ideals at issue in the controversies Hirschman and Holmes report play a smaller part in the debates of our own time. But in form these early defenses of desires and interests are responsive to any attempt to discredit them either as self-indulgent or self-defeating. Because such attempts remain common in our time, the defenses are pertinent to present concerns. ${ }^{18}$ The timeliness of yet wider moral and political views that were part of the thinking Holmes discusses is evident from a further passage from his work. When asserted against views such as Maistre's that "human individuality" is a "nullity" from God's point of view, "self-interest was a dimension of self-affirmation." Yet more broadly, it was important to the thinking of Constant and others of his time that interests "are distributed without regard to birth: they are just as independent of the social status of your family as they are of your religious beliefs. To act upon interest is to claim the status of an equal-of a masterless man." 19 Here we have much more than a defense of desires and interests against various traditional charges, much more than a claim that interests and desires do not have various unacceptable characteristics and consequences. In these formulations, developing, pursuing, and satisfying interests and desires are positive goods, are characteristics that deserve to be valued, protected, and promoted. They are made central to conceptions of individuality, of equality, and of freedom and hence are fundamental to a society suitable to human beings as liberals had come to conceive of them. We are not to apologize for our "desirousness" and "interestedness"; we are to insist on them.

These last views are in effect arguments for LP (or at least PNI) and GPF. They say that human beings have certain pronounced characteristics, and they make connections between those charac-

${ }^{18} \mathrm{Cf}$. Holmes: "Even today, antiliberal attacks on self-interest express nostalgia for systems of deference, authority, and condescension" (ibid.).

19Ibid., pp. 252-53. 


\section{Toward a Liberalism}

teristics and values that should be central to society. If analysis of "desires" and "interests" helps to defend these notions against certain persistent forms of attack, the linkage between them and equality and freedom not only legitimates but positively promotes them. Combining Hirschman and Holmes, we can say that the thinkers Holmes discusses were doing two things at once. They were promoting equality among and the freedom of individuals in a society that had begun to accept these values, but in which opposition to the values remained strong. In order to do so, they drew on the emerging legitimacy of desires and interests to affirm a notion of the individual for whom equality and freedom were appropriate. By tying the two sets of notions together, they gave support to both. And the resulting combination constitutes an argument for LP and GPF.

Of course this combination and hence this argument for LP and GPF can be and has been resisted. If Rawls and others are correct that an at least implicit commitment to freedom and equality is the distinctive feature of moral and political thought and practice in modern Western societies, then one of the pairs that form the combination has been generally accepted. And while it can hardly be denied that clesires and interests are widely regarded as legitimate, and are viewed yet more positively than this term suggests by many people in these societies, more and less vehement antidesires and anti-interests views remain familiar among us. Perhaps some who hold such views are also opposed to freedom and equality, but it is implausible to think that this is always or even commonly the case. We cannot assume that arguments for LP and GPF which depend on the combination just discussed will be generally convincing.

Let us reculer pour mieux sauter. Let us assume that Hirschman is correct in his claim that desires and interests have been recognized as prominent characteristics of the members of our societies and that these characteristics have been legitimated to the extent that generalized stigma no longer attaches to them. Forming, pursuing, and satisfying desires and interests may not have attained to the standing of prima facie goods, but they have shed the disrepute that once attached to them. (Or at least let us assume that the arguments supporting generalized hostility to desires and interests have been shown to be without merit and hence that in reason generalized stigma ought not to attach to them.) 
On these assumptions, a number of further arguments can be made for LP and GPF as normative principles. These arguments can be introduced by making a comparison. Consider the phenomenon of children, wives, employees, soldiers, and so forth who are told to "think for themselves," "take initiative," "be independent," and the like, but whose every thought and initiative is disapproved and rejected. Such people quickly learn either to dismiss as insincere the advice and await the forthcoming directives (perhaps simulating thought, initiative, and independence) or to rebel against the disapprovals and rejections and pursue their chosen courses as best they can. Either way, the practical incompatibilities among the demands made upon them are a source of severe and often damaging confusion and frustration.

There is a strong and positive analogy between this phenomenon and the situation that would obtain in a society that legitimated the formation and pursuit of desires and interests but that rejected LP (or at least PNI) and GPF. Encouraging an employee to think for herself and to take initiative does not commit superiors to agree with her every thought or to applaud the particulars of all the initiatives she takes. But doing the former in good faith creates, or rather carries with it, several presumptions. The most obvious of these are the presumptions that the superior believes that the employee is in fact capable of the kind of conduct in question (at least latently so) and that the superior genuinely encourages or perhaps authorizes her to engage in it. Taken together, these two presumptions carry a third, a guarded formulation (akin to PNI) of which is as follows: if the superior disapproves or rejects the employee's thoughts and initiatives, she must justify doing so and must do so in terms responsive to the particulars of the thoughts and initiatives in question. We might say that the superior must present such justifications in order to avoid engendering dissonance, exasperation, and the like in the employee. But since it is only very likely and not certain that these consequences will be produced, we should first say that in practical reasoning anyone who understands the first two presumptions will also accept the third.

The parallels between the first two presumptions and my Hirschmanesque assumptions about the recognition and legitimacy of desires and interests is clear enough (a possible difference being that legitimacy may be a weaker term than encourages or even authorizes in the second presumption). In the guarded form in which I 
stated the third presumption, something like Benn's PNI is more closely parallel to it than is LP. This is because neither PNI nor the third presumption as stated imply or even suggest a disposition positively to approve, or even an expectation that one very likely will approve, the content of the thoughts and initiatives. The idea is more formalistic; having licensed or authorized the thinking or the initiative taking, the superior is obliged to justify disapprovals and rejections of their content; having recognized and legitimated a tendency to form and pursue desires and interests, society is obliged to justify interferences with manifestations of that tendency.

The less guarded formulation of the third presumption parallels the more positive idea expressed by $\mathrm{LP}$ - that forming, pursuing, and satisfying desires and interests is prima facie a good. Having judged the employee capable of thinking for herself and of taking initiative, and genuinely approving of her doing so, the superior is disposed to approve her thought and her initiative or at least maintains a grounded expectation that she will approve of them. Rather than a mere, perhaps even a somewhat grudging, formal authorization, the superior has wholeheartedly and out of genuine conviction encouraged the thinking and the initiating. (The more positive formulation of the third presumption goes better with "genuinely approved" than with "legitimated" in the second presumption.) Her reasons for having done so create and support a disposition or expectation to approve the actual content of the thinking or of the initiatives. Society's reasons for recognizing and genuinely approving the formation, pursuit, and satisfaction of desires and interests carry over to and inform its response to the desires and interests actually formed and pursued. "Prima facie" does not mean "initially and formally but readily subject to justified exception"; it means "for good general reasons that are expected to hold in most cases albeit subject to the possibility of justified exceptions."

My claim, then, is that the legitimation of desires and interests charted by Hirschman and Holmes itself supports an argument that goes beyond legitimation. In the weaker forms that stop at rebutting generalized objections to desires and interests, the legitimation of the latter supports PNI and GPF. It does so in the internalist sense that those who understand and accept the legitimation and the reasons for it will understand and accept PNI-GPF and also in the consequentialist sense that accepting legitimation but rejecting PNIGPF will very likely create confusion, frustration, and conflict. In 
the stronger formulations involving genuine approval of desirousness and interestedness (for example, those formulations that link desires and interests closely to freedom and equality), legitimation itself supports LP in both the internalist and the consequentialist renderings of "supports." In short, to reject PNI-GPF or LP-GPF, one would have to adopt some version of the views that come to be rejected in the period studied by Hirschman and Holmes and that comport very badly with the present logic of "desires" and "interests." At a minimum we are entitled to conclude that generalized anti-interest and antidesire arguments are either confused or deeply radical in the sense of rejecting an interwoven and mutually reinforcing set of beliefs and values which is very firmly established in modern Western societies. In a society that recognizes and has legitimated desires and interests, LP is appropriate at least as a principle of mutual toleration or a weak principle of equality. In a society that genuinely respects individuality and diversity, certainly in one with a genuine enthusiasm for them, it recommends itself much more strongly. If desires and interests are in fact among our salient characteristics, and if we genuinely accept and value this fact about ourselves, we will accord one another's desires and interests the presumptions expressed in and required by LP.

\section{III}

If it is easy to list moralists who object to desires and interests, it is difficult to identify any who object to "end-seekingness" and purposiveness. Neither "end" nor "purpose" has been associated with passion, impulses, and other subjectivist or even "animal" notions that are prominent features of the literature concerning desires and interests. It is true that virtue-, duty-, and rights-oriented theorists argue that the pursuit of the ends and purposes we form should be disciplined by principles and rules of conduct that are in some sense independent of those ends and purposes. It is also true that teleological and consequentialist theories that reject or seem unable to accommodate such disciplining principles and rules have been much criticized. But virtue theorists identify the virtues they promote as qualities of character that are necessary or strongly conducive to the achievement of certain end states judged to be suitable to human beings at their best; most deontologists have allowed that the con- 


\section{Toward a Liberalism}

straints of duties and of rights, even if in some sense self-justifying, are constraints on end-seeking, purposive activities and would have no application to creatures who do not engage in such activities. ${ }^{20}$

The fact that LP includes ends and purposes among the prima facie goods means that, formally or conceptually, it has room for, it can accommodate, the as it were positive concerns or objectives just mentioned. When combined with the foregoing arguments about desires and interests this suggests that, formally, LP should prompt few if any objections. Indeed, in respect to the more individualist of the rights-oriented deontological theories, we can make the stronger claim that something akin to LP is presupposed by them. Rights are discretionary, not mandatory; they leave it to the right bearer to determine whether to take the class of actions that the right protects. At a minimum, this allows that agents may make these determinations on the basis of their ends and purposes as they see them. If end-seeking, purposive conduct were not at least a prima facie good, it is difficult to see how such discretion could be justified. In this perspective, decisions to establish rights are based on judgments that certain classes of ends and purposes are especially important and deserve not merely the protection afforded by LP and GPF (the protection afforded by a right in the sense of a "liberty" in Hohfeld's schema), ${ }^{21}$ but the further protection afforded by a right (a "claim-right" or "right in the strict sense" in the Hohfeldian vocabulary).

But proponents of the doctrines just mentioned typically argue not for end seeking or purposiveness as such, but for particular, more or less definite ends or purposes that they regard as embodying the ideals or excellences of human life. In the moderately technical language now current, proponents of these doctrines are advocates of perfectionism. ${ }^{22}$ Accordingly, the fact that LP includes an endorsement of "ends" and "purposes" in abstract, generic terms is not likely to heighten their enthusiasm for it. Perfectionists cannot

\footnotetext{
20See esp. John Rawls, "The Basic Liberties and Their Priority," in The Tanner Lectures on Human Values, vol. 3, ed. S. M. McMurrin (Salt Lake City: University of Utah Press, I982), p. 49; "Kantian Constructivism in Moral Theory," Journal of Philosophy 77 (1980):530.

21See Wesley N. Hohfeld, Fundamental Legal Conceptions (New Haven: Yale University Press, I919).

22I believe that the concept acquired its present prominence because of its central place in Rawls's work. See A Theory of Justice (Cambridge: Harvard University Press, I97I), esp. p. 25 and sec. 50.
} 


\section{Liberalism and Freedom}

deny that LP as an axiological principle formally encompasses the ends and purposes they favor. Nor can they deny that an argument for freedom of action grounded in LP will provide support for freedom to pursue those ends and purposes. But they will surely object that the support it offers for those freedoms is much too weak, and they surely will also object that it offers at least initial support for freedoms that are insupportable. The axiological principles of society should coincide with the inventory of substantive ends and purposes that perfectionists favor (or at least the axiological principles should exclude all ends, purposes, and other reasons for action that conflict with pursuit of the ends and purposes perfectionists favor).

As a first step in assessing these objections, it will be helpful to consider the case of freedom of religious belief and practice. For people who are indifferent about religion, the religious desires and interests, ends and purposes that people in fact have and pursue are as eligible for the standing of prima facie goods as any other. Moreover, according a wide freedom for religious practice may diminish conflicts that might prevent or inhibit other activities supported by LP.

But what about people who are convinced that their beliefs, whether pro or antireligion, are true not merely in the sense that they themselves hold them but simply or unqualifiedly? Consider the atheist who is satisfied that she has conclusive arguments against the existence of a divine being and who is also convinced that all forms of religiosity are worse than vulgar superstition. Or consider the believer who is "morally certain" of the truth of her specifically religious beliefs and who is equally convinced that irreligiosity and religious diversity make so much as decency impossible in human society. For such people religious freedom will seem much worse than a poor thing. How can it be, even prima facie, a good thing to maintain practices that are false and harmful? How can society allow, let alone endorse as a good, ends and purposes that lead to action destructive of human well-being?

Of course atheists and believers can accept a generous religious freedom as a lesser evil. If it has proven to be genuinely impossible to win general acceptance of the beliefs and practices that are true and good, we retreat to that arrangement to protect such truth and goodness as obtains among us, and we regretfully pay the price of tolerating beliefs and practices known by us to be false and harmful. 


\section{Toward a Liberalism}

But we do not pretend that what we know to be false is prima facie true or that what we know to be harmful is prima facie good. Indeed, we do not pretend that the arrangement that protects the false and the harmful is anything better than an unfortunate necessity, an evil that we accept because it is least among the evils with which we are confronted. (Somewhat more positively, the arrangement might be defended as a way of buying time. By protecting the good practices that exist among us we preserve the possibility that example and argument will win converts enough to permit us to advance to something better.)

Perfectionist positions in respect to moral and political questions. are analogous to (albeit not necessarily fully parallel with) the position of the atheist and believer as just discussed. There are ends and purposes that are good simply or all things considered, not merely prima facie. There are others that are clearly wrong or harmful or evil. In the latter cases the burden of justification falls on anyone who proposes to pursue those ends and purposes, not on those who object to them. How we should go about promoting good ends and purposes, and how dispositions and attempts to pursue bad or evil ones should be discouraged or prevented, are of course further questions. But actions and arrangements that are means to achieving good ends take at least initial justification from that fact about them, and actions and arrangements that are means of preventing the pursuit or achievement of evil ends take initial justification from that fact about them. Insofar as perfectionists have concerned themselves with freedom, freedom to pursue good ends is easily justified; certainly freedom to pursue evil ends is objectionable and restrictions on such freedom are easily justified.

As with strongly convinced atheists and with religious believers in respect to freedom of religion, convinced moral and political perfectionists might accept or accommodate themselves to a view of freedom that maintains wide latitude in the pursuit of individual ends and purposes. They could accept moral and political toleration as a lesser evil or as a temporizing device. Society averts its glance, at least its organized, collective glance, from much that is undoubtedly objectionable and even harmful, reserving its collective notice and its collective, authoritative action to the most directly and seriously harmful activities of its members. Nevertheless, within the compass of their perfectionism - that is, in respect to the ends and purposes that they judge to be undeniably evil or harmful-a moral and 


\section{Liberalism and Freedom}

political perfectionist must regard such arrangements as no better than arrangements of toleration. They can no more cherish or delight in such arrangements and the freedoms of action they recommend than the deeply committed atheist or believer can cherish or delight in freedom of religious belief and practice.

\section{IV}

My remarks about ends and purposes are overly schematic in respects that would have to be remedied in a full discussion. For one thing, there are numerous versions of perfectionism, and it would be wrong to suggest that they all involve the same stance toward or the same implications concerning LP and GPF. (Consider, for example, the difference among T. H. Green and Friedrich Nietzsche, Alasdair MacIntyre and Hannah Arendt. Each of these writers is plausibly regarded as a perfectionist in Rawls's sense, but their conceptions of the good or ideal to be pursued, their conceptualizations of freedom, and their assessments of the value of freedom or various freedoms to achieving the good or ideal, vary widely.) For another, there are well-developed positions that reject both LP-GPF and perfectionism.

I cannot discuss these variations in detail, but I suggest that they share an objectionable feature, namely, privileging certain ends or purposes so strongly as to categorically exclude the possibility of justifying actions (and hence freedom to take those actions) which conflict with the preferred ends and purposes. I conclude by developing and briefly defending this suggestion by reference to a view, that of John Rawls, which sharply challenges my argument but does so from a position that shares many of the assumptions from which I have been arguing and a number of the conclusions I have drawn.

Although allowing that his theory includes "ideal-regarding" as distinct from "want-regarding" principles, ${ }^{23}$ Rawls rejects perfectionism in the sense of views that claim there is a single substantive conception of the good that ought to be accepted by all persons and that should be adopted and implemented by politically organized societies. ${ }^{24}$ But he also rejects, or rather sharply qualifies, LP and

23Ibid., pp. 326-27.

24Ibid., pp. $326 \mathrm{ff}$., 4 I 4 ff. 


\section{Toward a Liberalism}

GPF, arguing against them that interests and desires that conflict with the principles of justice deserve no consideration and that freedom to pursue such interests and desires can never be justified. ${ }^{25}$

It is important to recognize that Rawls's principles of justice hold only in respect to the "basic structure" of politically organized society, and that outside of the ambit of that structure he endorses a position very close to the one I have presented here. As the term itself tells us, however, the basic structure includes the principles, institutions, and practices fundamental to social life, those that do more than any others to influence the thought and action, the purposes and prospects of everyone in society. ${ }^{26}$ Seen in this light, the categorical restrictions that his theory imposes on LP and GPF are by no means marginal or inconsequential.

For reasons already discussed, we cannot treat freedom of action to pursue interests and desires, ends and purposes, as a good that can never be subordinated to any other objectives or principles. Rawls's theory is not objectionable because it argues for justicebased rankings of and restrictions on freedoms. Nor, in my view, is the content of Rawls's proposed principles of justice seriously objectionable. In its abstract formulation the first of those principles is at least akin to GPF in that it is a principle of equal liberty, and Rawls's elaboration of it yields a familiar and to my mind quite eligible short list of basic liberties. ${ }^{27}$ The second principle is more disputable (and much disputed), but it is worth noting not only that it is subordinate to the first principle but that it is defended in part as necessary to making the first principle effective. ${ }^{28}$

The difficulty, rather, is that Rawls rigorously excludes the possibility of revisions in, and/or circumstantially justified departures from, the rankings of and restrictions on freedoms of action that his theory proposes. The principles of justice are in lexical order, and justice itself is accorded strict, invariable priority over all other considerations. The justice-based basic liberties have the standing not merely of constitutional rights, but of pre- or extraconstitutional principles that could be revised, reconsidered, or justifiably

${ }^{25}$ See ibid., p. 3 I, for an especially severe statement. Cf. Rawls, "The Basic Liberties and Their Priority," p. I7I; and "Kantian Constructivism in Moral Theory," p. 527.

26See Rawls, $A$ Theory of Justice, pp. 7, 259.

${ }^{27}$ See Rawls, "The Basic Liberties and Their Priority."

28See ibid., esp. sec. 7 . 


\section{Liberalism and Freedom}

violated only (so long as "reasonably favorable conditions" obtain) as a part of the deeply radical activity of rethinking the entire basic structure of society. We are to privilege some and restrict other freedoms not merely by accepting social and moral conventions, by adopting constitutions. and promulgating laws, but in the much stronger sense of committing ourselves unqualifiedly and into the indefinite future to principles and institutions that embody them which we will thereafter regard as beyond justifiable violation and all but beyond reconsideration.

My argument for LP and GPF is of course an argument against any such commitment. If human beings and their circumstances are as I have described them, and if modern Western culture has (at the least) recognized and legitimated those characteristics and features, then Rawls's scheme presents itself as severe, uncompromising, and perhaps alien. For limited but crucial purposes openness to and celebration of the possibilities of freedom of action are replaced by unyielding rejection of large classes of interests and desires and of actions taken to serve and to satisfy them; within the realm of social justice impulses and tendencies to diversity and change are not only subject (as they must be) to disapproval and prohibition by (disputable and revisable) public judgment and by the (contestable) decisions of (replaceable) public officials, but categorically excluded by principles that are to be regarded as immune to reconsideration in or through the processes and procedures of moral, constitutional, and political discussion and debate. In its most basic respects the realm of freedom is not to be settled, unsettled, and settled and unsettled anew; it is to be settled once and for all. We are to deprive ourselves of the freedom that is arguably the most fundamental of all, the freedom to go on deliberating the scope of our freedom.

Rawls advances a number of arguments of an affirmative character for his principles of justice and for the extraordinary standing he assigns them. He proposes a conception of moral personality featuring two "moral powers" (a sense of justice and the capacity to form a conception of good) and two corresponding "highest-order interests" (roughly, interests in developing and using the two moral powers), ${ }^{29}$ and he argues for a "thin" theory of the good according to which there are certain "primary" or all-purpose instrumental goods that are necessary to the satisfaction of the highest-order

${ }^{29}$ Rawls, "Kantian Constructivism in Moral Theory," sec. 7; “Justice as Fairness," pp. 233-34. 


\section{Toward a Liberalism}

interests and in particular to realizing any and all conceptions of the good. ${ }^{30}$ In this perspective, the rigorism of his position presents itself as a function of his conception of moral personality and its needs.

These affirmative arguments for the absolute weight of justice and the strict lexical ordering of the two principles of justice may or may not be vulnerable to Rawls's own strictures against perfectionist views. (As noted, Rawls allows that his theory includes ideals, but claims that it is not perfectionist because it does not advance a substantively determinate conception of the good to be adopted by everyone.) For present purposes the more important point is twofold. First, we could accept Rawls's conception of moral personality and its needs and yet reject his rigorism. Accepting the former would dispose us to the basic structure Rawls proposes, and we might in fact create and sustain a constitutional system instantiating that structure. But we would insist that the features of that structure must remain open to reconsideration both in the sense that the principles might be revised so as to better serve the needs to which the structure is instrumental and in the further sense that particular circumstances might justify refusals to act in the manner specified by the principles. (The principles would be regarded as constitutional, not pre- or extraconstitutional, and there would be a constitutional procedure for amending the constitution; civil disobedience and what I have elsewhere called "civil encroachment" on rights ${ }^{31}$ would have an accepted place in constitutional and political theory.)

Second, Rawls acknowledges the possibility just canvassed, at least in the sense that he advances another, negative, argument for his rigorism, an argument that appeals less to the affirmative merits of his conception of moral personality and his principles of justice than to the consequences of adopting a less rigorist approach. ${ }^{32}$ The sort of mobile, amenable, latitudinarianism proposed here, he argues, depends on an unworkable form of "intuitionism," on the unwarranted assumption that conflicts such as those among freedoms and between freedoms and other values can be successfully

${ }^{30}$ Rawls, $A$ Theory of Justice, sec. I 5; "Kantian Constructivism in Moral Theory," pp. 525-27; "The Basic Liberties and Their Priority," pp. 2Iff.

${ }^{31}$ Chap. 5 in this volume.

32Rawls, $A$ Theory of Justice, sec. 7, pp. 3 I 5 ff.; "The Basic Liberties and Their Priority," pp. Iо, 26, 32, 74; and "Justice as Fairness," p. 258. 


\section{Liberalism and Freedom}

resolved circumstantially, that is, by resort to the unsystematized (or less systematized) moral and political intuitions that have developed out of our socialization, acculturation, and education. Of course in Rawls's own thinking this negative argument is connected with the affirmative one just discussed; the (in Rawls's mind) predictable failure of reliance on intuitions is objectionable first and foremost because of the effects it would have (has) on the moral powers and the highest-order interests that go with them. But the force of the negative argument need not depend on acceptance of the affirmative one. One need not subscribe to Rawls's conception of moral personality or his theory of the good in order to object to intractable conflict, arbitrary imposition, and the other barriers to fair cooperation that, according to Rawls, are certain to attend unconstrained intuitionism. By introducing this negative argument Rawls encourages the thought that the case for rigorism is separable from the case for his principles of justice. While it is surely not his view that any rigorist scheme would be preferable to intuitionism, his objections to the latter constitute his most general challenge to the view I have advanced here.

The affirmative arguments for the latter view presented in sections I-III of this essay require rejection of neither Rawls's conception of moral personality nor his principles of justice. Those arguments do require that we recognize the conception as a moral ideal, one that may or may not be judged superior to other ideals. They also require that we view the principles of justice as instrumental to the ideal and hence revisable and defeasible, even if allegiance to the ideal is general and constant. Those arguments promote an openness to possibilities not only as regards life-styles and patterns of conduct outside of the basic structure but concerning social and political structures, arrangements, and practices. Although hardly agnostic about general human characteristics and values, even in this respect they are culture-specific, not transcendental or universalist, and they otherwise express a moderate skepticism intended (among other things) to protect freedom from overweening philosophical and ideological claims, from kinds of dogmatism that issue (as my arguments themselves do) from the urge to general theory. True, they leave the question of whether in other respects freedom will be adequately secured to interactions among moral and political agents taken as we find them in the settings in which they live their lives. If - as I think - this is a liberal conception of the role of 
political philosophy in political practice, it is indeed likely that political practices informed by it will continue to feature the disagreement and conflict that Rawls regrets and seeks to contain. But even if it is within the powers of political philosophy to institute the fuller accord and greater harmony that Rawls seeks (which is of course unlikely), it would be objectionable for it to do so. 